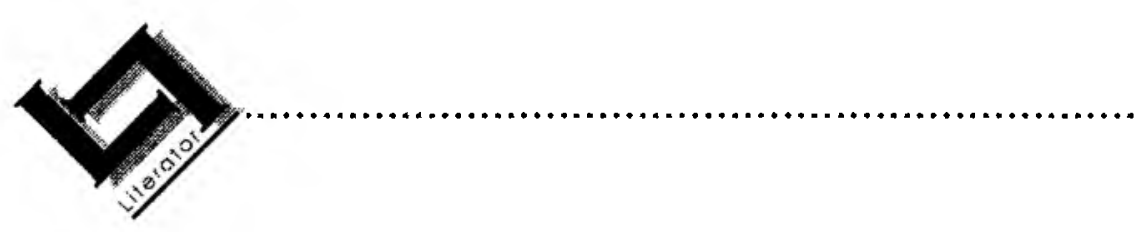

\title{
Die mites oor Afrikaans: 'n inleidende beskouing oor die persepsie van Afrikaans as onderdrukkerstaal
}

\author{
Marlene Verhoef \\ Skool vir Tale \\ Vaaldriehoekkampus \\ Potchefstroomse Universiteit vir $\mathrm{CHO}$ \\ VANDERBIJLPARK \\ E-pos: aftmmv@puknet.puk.ac.za
}

Daar kan eers hoop vir 'n nuwe en dinamiese toekoms gewek word as die mites van Afrikanerskap en Afrikaans tot op sy been gedekonstrueer word, vernuwe word en ons weer begin bou aan 'n nuwe paradigma.

(D C. du Toit, Die Burger, 1998-05-08)

\begin{abstract}
Myths about Afrikaans: a preliminary reflection on the perception of Afrikaans as language of oppression

The myths surrounding Afrikaans have developed over a period of time and can be seen as unjustified assumptions which are generally accepted. The aim with this article is to provide a generic theoretical framework against which perceptions of languages can be assessed. Particular attention is also given to the analysis of the prominent stereotyped opinion of Afrikaans as language of oppression according to the given theoretical paradigm.
\end{abstract}

\section{Kontekstualisering}

Hans du Plessis (1992b:69-70) sê dat wanneer daar besin word oor die toekomsverwagtinge van 'n taal, die wisselwerking tussen taal en spreker nie uit die oog verloor mag word nie. Dit word ook duidelik uit Swanepoel (1992:123) se beredenering dat daar 'n oorsaaklike verband aan te toon is tussen die positiewe of negatiewe emosies wat sprekers oor 'n taal en sy gebruikers ervaar én die toekoms van daardie taal. Edwards (1994:89) sê selfs mense se sienings 
van 'n betrokke taal word grootliks bepaal deur die voor- of afkeur wat hulle teenoor die sprekers van sodanige taal het. Hierdie persepsies van 'n taal se sprekers beïnvloed die reaksie teenoor die taal en dít het bepaalde implikasies vir die toekomsverwagtinge van die taal, ongeag van wat in die amptelike taalbeleid geponeer word.

Hierdie standpunt van Edwards (1994:89) gee perspektief op die posisie van Afrikaans in die Suid-Afrikaanse taalpolitiek: op grond van die manier waarop die sprekers van Afrikaans gesien is, is bepaalde persepsies oor die taal gevorm. Hierdie persepsies het mettertyd geyk geraak, en is net so van toepassing op taalsake gemaak. Uiteindelik is hulle moeilik om te verander, ten spyte van die grootskaalse politieke transformasie in Suid-Afrika - en ondanks die feit dat Afrikaans, sy amptelike status as een van elf landstale ten spyt, swaarkry om dié posisie op alle samelewingsvlakke te handhaaf: Herman Giliomee (Die Burger, 1999-03-22) sê duidelik dat die toekoms van Afrikaans as taal en kultuur in 'n baie belangrike mate afhang van "n regering wat histories geen rede het om besonder lief daarvoor te wees nie" - en impliseer daarmee dat die voortgang van Afrikaans oor méér gaan as die grondwetlike taalartikels wat meertaligheid propageer.

Dit is boonop noodsaaklik om uit taalsosiologiese hoek kennis te neem van persepsies oor taalsake omdat die suksesvolle praktiese implementering van die taalartikels in die Grondwet (Wet 108 van 1996) grootliks afhang van sosiopsigologiese faktore soos dié. Daarby behoort 'n teoretiese besinning oor taalpersepsies, stereotipes en taalmites ook rigtingwysend te wees vir die voortgang van die taalbeplanningsproses in Suid-Afrika.

Die oorhoofse doel met hierdie artikel is om te fokus op die teoretiese begronding van taalpersepsies - spesifiek van Afrikaans - vanuit die sosiopsigologie en aanverwante dissiplines. Hierdie fundering behoort 'n nuttige navorsingsraamwerk te bied vir die studie van taalpersepsies en behoort te verseker dat die emosionele aard van die gesprek oor dié aspek van taal geneutraliseer word.

Ten einde die voorafgaande algemene doelstelling te bereik, moet daar helderheid bereik word oor die volgende sake:

- wát persepsies is, hoe dit gevorm word en waaruit dit op gesaghebbende en verantwoordbare wyse afgelei kan word;

- op watter wyse mites tot stand kom en watter aanleidende rol die dinamika tussen oortuigingsraamwerke, vooroordele en stereotipes speel in die vorming daarvan, en 
- tot watter mate die geykte simboliese vergestalting van Afrikaans as onderdrukkerstaal en die ontmitologiserende vergestalting van Afrikaans as bevrydingstaal ontleed en afgelei kan word uit uitlatings wat algemeen oor Afrikaans gemaak word.

\section{Persepsies van Afrikaans onder die vergrootglas}

\subsection{Teoretiese begronding}

Die woord persepsie kom uit die Latynse per + capere (= neem) en dui op die proses en resultaat waardeur indrukke in die bewussyn opgeneem word (HAT, 1994:794). Nel (1992:10) sê die werkwoordelike vorm van die woord is afgelei van die Latynse percipere wat in Engels vertaal kan word met to lay hold of, seize, to collect, gather, harvest. Die afgeleide naamwoordvorm is perceptio wat in Engels omskryf kan word as receiving, grasping, gathering together.

Hy waarsku egter dat persepsievorming nie slegs gesien moet word as 'n mentale proses wat deur die sintuie gevoed word nie, maar dat dit primêr gesien moet word as 'n semantiese konsep: "Perception' as a meaning concept refers to the way people use language and other symbolic tools to attach value and significance to other people, their values and intentions, and their behaviour" (Nel, 1992:10).

Só gesien, word dit duidelik dat die persepsiekwessie 'n belangrike sosiale kollektiewe dimensie het. Let op die volgende voorbeelde ter illustrasie van die krag van openbare mening wanneer persepsies gevorm word:

Koos du Toit (Die Burger, 1998-04-23) voer aan dat Afrikaans in 1998 steeds 'n stryd voer om homself van die etikette van verdrukkerstaal en apartheidstaal te bevry.

'n Redaksionele artikel in Saturday Star (1998-03-07) beredeneer die feit dat Afrikaans medeverantwoordelik gehou moet word vir die feit dat swart SuidAfrikaners se reg om persoonlike keuses uit te oefen, vernietig is.

Randall van den Heever en Melanie Verwoerd (Die Burger, 1998-04-20) sê dat aktiviste geglo het dat Suid-Afrika se bevryding afgehang het van die mate waarin Afrikanerkultuur vernietig is (en gee per implikasie toe dat Afrikaans ook hierby betrek is), maar sê dat die nuwe grondwet van Suid-Afrika voorsiening maak vir die opheffing van Afrikaans: "Afrikaans se status is onteenseglik verryk as taal wat op eie bene kan staan midde-in die polsende dinamiek van 'n veeltalige en multikulturele land."

Die doel met die volgende afdeling is die daarstel van 'n teoretiese paradigma aan die hand waarvan waargenome taalpersepsies verstaan en beoordeel kan word. 
Brown (1995:78-79), 'n sosiopsigoloog, verduidelik dat persepsies gevorm word aan die hand van 'n kognitiewe organisasieproses waardeur die indrukke wat mense oor 'n saak het én die gehuldigde oortuigings daaromtrent 'n bepalende rol speel in die wyse waarop mense hul omgewing en leefwêreld kategoriseer en benoem. Dit gaan daarom dat dié kognitiewe kategoriseringsproses mense/ waarnemers in staat stel om, vanweë die samespel van verskeie sosiale faktore, of te assosieer, of te dissosieer met 'n bepaalde groep mense en sake wat met hulle verband hou. Dit beteken dat verskille oor die hoof gesien sal word in 'n kategoriseringsproses indien die waarnemer homself beskou as deel van die binnegroep/"ingroup" en dat die soeke na sake van gemeenskaplike belang in die sentrum sal staan. Verskille sal egter op die spits gedryf word indien die waarnemer hom distansieer van 'n bepaalde saak/aangeleentheid/persoon en dit as buitegroep/"outgroup"-bedrywighede sien - met ander woorde, indien die waarnemer, as gevolg van 'n verskeidenheid redes, homself stel téénoor die aangeleentheid ten opsigte waarvan die kategoriseringsproses plaasvind.

Die kategorisering van die indrukke en oortuigings vind plaas op grond van 'n basiese ingesteldheid waardeur die individu die gegewe aangeleentheid beoordeel. Hierdie beoordeling geskied op grond van die waarnemer se eie onmiddellike behoeftes, oortuigingsraamwerk en ervarings van 'n betrokke saak en die posisionering vanuit binne- of buitegroepperspektief. Kortom, by die vorming van persepsies gaan dit dus om die mate waartoe 'n individu die saak waaroor 'n oordeel gevorm word, as kognitief-toeganklik beleef en die mate waarin dit met sy eie oortuigingsraamwerk korreleer. Uiteindelik is dit hierdie beoordelingsproses wat daartoe lei dat mense persepsies oor sekere sake/ aangeleenthede/persone huldig.

Nel (1992:3) voer aan dat, hoewel die begrip persepsies geredelikerwys gebruik word as sambreelterm wat na 'n aantal kognitiewe veranderlikes verwys, dit eerder gesien moet word as 'n stel evaluatiewe aktiwiteite waartoe toegang verkry word indien mense se optrede en die motivering ter regverdiging van die optrede, in oënskou geneem word. Dit kom dus voor of persepsies, hoewel dit, volgens Swanepoel (1992:152), ook met die begrippe houdings/gesindhede benoem kan word, in werklikheid die brug slaan tussen wat mense sê en wat hulle doen.

In die ondersoek van die persepsies van Afrikaans en die Afrikaanse taalgemeenskap is dit vervolgens belangrik om te bepaal wát hierdie persepsies is, hóé dit tot stand gekom het en watter bydrae hierdie inligting kan lewer wanneer dit gaan om die beoordeling van dié taalpersepsies. Hierdie proses behoort nie alleen heuristiese waarde te hê nie, maar het ook die potensiaal om 'n belangrike rol te speel in die ontmitologisering van Afrikaans. As aanloop tot die uitklaring van die ontmitologiseringsproses is dit belangrik dat eers kennis geneem word van die wyse waarop mites gevorm word. 


\section{Perspektief op die vorming van mites: 'n samespel tussen vooroordele, stereotipes en persepsies}

\subsection{Inleidend}

Volgens Steenberg (1992:312-3) kan die begrip mite op talle maniere omskryf word en is die verskillende interpretasies daarvan te danke aan uiteenlopende invalshoeke by die ondersoek van mites. Tog kom dit voor of mites oor die algemeen die volgende eienskappe vertoon: dit dui dikwels op versinsel, het 'n relatiewe karakter, vertoon konnotasies met die onbewuste, geniet algemene aanvaarding deur die gemeenskap waarbinne dit leef en vertoon 'n standhoudendheid oor die tyd heen (Steenberg, 1992:313).

Daarenteen beweer Fourie (1991:3) dat die begrip mite "nie soseer 'n onwaarheid bedoel nie, maar dui (op) 'n sosiaal-gekonstrueerde waarheid". Hy bedoel hiermee dat mites verwys na die onkritiese algemene aanvaarding van gebruike en opvattings wat oor 'n tydperk inslag in 'n gemeenskap gevind het.

Pokpas en Van Gensen (1992:173) voer aan dat mites sekere idees of persepsies verabsoluteer en dat kunsmatige waarde daaraan geheg word: "Mites kweek en bestendig eintlik populêre waardes en meningsuitsprake van vervloë jare". In aansluiting hierby redeneer Swanepoel (1992:131 e.v.) dat die begrip mite se omgangsbetekenis kan dui op vals aannames/opvattinge.

Hierdie eendersklinkende verklarings van die begrip mite gee perspektief op die geykte, onkritiese aanvaarding van die simboolwaardes dat Afrikaans as voertuig vir Afrikanernasionalisme opgetree het; dat die taal, vanweë die feit dat Nasionale Party-bewindhebbers hoofsaaklik Afrikaanssprekend is, met die apartheidsbeleid geasossieer geraak het en dat hierdie verbintenis gelei het tot die etiket van verdrukkerstaal.

Aangesien mites op húl beurt deur vooroordele, stereotipes en persepsies gevoed en gedra word, is dit noodsaaklik dat dié begrippe in perspektief gesien word. Dit is egter baie belangrik om, in die beskouing van hierdie begrippe, rekening te hou met die feit dat dit 'n komplekse sosiale verskynsel hoegenaamd nie monolities beskou kan word nie. Daarom word veronderstel dat begrip daarvoor slegs gekweek kan word indien 'n mens aanvaar dat die vorming van mites gesien word as 'n ineengeweefde, interafhanklike dinamika tussen die historiese, politiese, ekonomiese en sosiale kragte in 'n bepaalde konteks.

\subsection{Vooroordele, stereotipes en persepsies van Afrikaans}

Brown (1995:14-15) gee toe dat vooroordele op verskillende maniere gedefinieer word, maar sê dat dit gewoon gesien kan word as 'n spesifieke emosie, gesindheid of optrede teenoor individue/sake/aangeleenthede op grond van die aard van die verwantskap met die groep wat met die betrokke geval 
geassosieer word. Hier is dus van 'n kategoriseringsproses sprake waardeur, op grond van maatstawwe wat die beoordelaar sélf aanlê (onder andere vanweë sy oortuigingsraamwerk en ervarings met dié saak in die verlede) positiewe of negatiewe oordele uitgespreek word. Dit is duidelik uit Oakes et al. (1994:3031) se beredenering dat die kategoriseringsproses grootliks bepaal word deur die mate waarin die beoordelaar die saak onder oordeel vanuit 'n binne- of 'n buitegroepperspektief beleef: wanneer individue/aangeleenthede wat met binnegroepkategorieë geassosieer word, beoordeel word, sal daar geredeliker aanvaarding vir standpunte/werkwyses wees, terwyl individue/aangeleenthede wat met buitegroepkategorieë geassosieer word, met agterdog bejeën of gewantrou word. Uiteindelik lê dit voor die hand dat hierdie kategoriseringsproses vanuit of die binne-, of die buitegroepbetrokkenheid 'n rigtende invloed uitoefen op optrede teenoor sodanige individue/aangeleenthede.

Die volgende aanhalings waardeur oordeel oor Afrikaans uitgespreek word, bewys dat daar eerstens binne- en buitegroepkategorisering ten opsigte van die posisionering teenoor die Afrikaanse taalkwessie bestaan, en tweedens dat hierdie kategorisering nie noodwendig met primêre en sekondêre taalgemeenskapverbintenis gepaard gaan nie:

1. Carel Boshoff (Beeld, 1994-11-05) vra: Kan 'n mens jouself wees buite jou taal en jou gemeenskap? Buite jou familie en jou geskiedenis? Om betekenisvol te lewe, moet 'n mens kan vra wat betekenis is, en dit kan 'n mens slegs doen teen die horison van jou eie lewe. Afrikaners het die reg op hulle eie geskiedenis, al is hulle wit. Ons het die reg op ons eie taal (selfs ons eie vôriôsie - sic.) al is ons middelklas. Ons kan aanspraak maak op die dinge wat ons lewe betekenis gee, ons rituele en tradisies, ons verenigings, ons gesinne, ons onderwys. Wat nie beteken ons kan enigiemand dwing om van ons te hou nie - dis 'n saak wat sy eie eise stel, maar dit sal help as ons lewe asof God ons nie alleen geroep het nie, so asof ons aansprake die enigste aansprake is wat tel nie.

2. Afrikaanssprekendes wat bekommerd is oor die statusafname en toekoms van Afrikaans, moet besef dat hulle slegs hul taalregte sal kan beskerm as hulle dit binne die raamwerk van veeltaligheid doen (Neville Alexander, ondervoorsitter van PANSAT, Die Burger, 1997-05-29).

3. Die Taal is 'n replika van die outonomie van die Afrikaner as volk en 'n portret van die volk se karakter ... Daarom is Afrikaans so 'n groot probleem in die nuwe Suid-Afrika. Wat die protagoniste inspireer, is maar net hierdie ou mite dat as daar niks anders oorbly nie, is die Afrikaner se outonomie geleë in sy taal en godsdiens, om hom te beskerm teen die patologiese vrees vir 'verengelsing' en 'swart oorheersing' (Dirk C. du Toit, ANC-LP, Die Burger, 1998-05-08). 
Dit word uit die taalgebruik - spesifiek wat die gebruik van die voornaamwoorde betref - in die voorafgaande drie aanhalings duidelik dat die eerste een vanuit 'n binnegroepperspektief gestel word, terwyl die tweede en derde aanhalings die Afrikaanse taalkwessie vanuit 'n buitegroepperspektief waarneem.

Ten opsigte van die verwantskap tussen stereotipes en vooroordele voer Fourie (1991:3) aan dat stereotipes bloot bestaan ter wille van die rasionalisering van vooroordele, dat vooroordele deur hulle versterk en ondersteun word en dat teenstrydighede bloot deur stereotipes geïgnoreer word. Baron en Byrne (1991: 197) verduidelik dat stereotipes in wese kognitiewe raamwerke is wat grootliks gevorm en bepaal word deur kennis van en oortuigings oor 'n bepaalde aangeleentheid. Hierdie raamwerke tree as't ware as filters op en oefen 'n bepalende invloed uit op die wyse waarop inkomende indrukke en inligting geprosesseer word. Volgens Oakes et al. (1994:1-2) kan stereotipering as 'n vereenvoudigingsproses gesien word waardeur die komplekse werklikheid hanteerbaar gemaak word. Eenvoudig gestel, is dit 'n proses waardeur sekere attribute/ eienskappe bloot aan individue/sake toegeken word op grond van hulle assosiasie met 'n sekere groep van wie kollektief geglo word dat 'n sekere eienskap gedeel word. Dit beteken dat die waarnemer op subjektiewe wyse besluit (al is daar nie grond vir sodanige besluit nie) dat sekere individue/sake eenderse eienskappe met één groep mense deel en daarom ánders as ander groepe mense is. Op grond van dié gewaande onderskeid word individue wat aan sodanige groepe behoort, dan verskillend behandel.

Dit word dus duidelik dat stereotipering in wese 'n groepsgebaseerde aangeleentheid is waar dit gaan om die beoordeling van individue/aangeleenhede op grond van die toekenning van groepskenmerke en 'n gepaardgaande simboolwaarde daaraan. Op dié manier word die uitsprake of optrede van individue beskrywe, geïnterpreteer of voorspel op grond van die verbintenis daarvan met die groep (Oakes et al., 1994:102). Tog word daar volgens dié skrywers aangevoer dat daar in die laaste tyd van die standpunt uitgegaan word dat stereotipes nie vaste kognitiewe voorstellings is nie, maar konteksgevoelige raamwerke aan die hand waarvan attribute aan individue/aangeleenthede toegeken word op grond van wat aktueel in die huidige tydsgewrig en in die sosiale konteks is.

Die voorafgaande bespreking werp lig op die stereotipering van Afrikaans en Afrikaanssprekendes waarvan Webb et al. (1992:41-2) melding maak en wat dit stel dat Afrikaanssprekendes as "streng, outoritêr en onsimpatiek gesien is, en Engelssprekendes as vriendelik en simpatiek". Hierdeur is dit duidelik tot watter mate 'n kognitiewe kategoriserings- en vereenvoudigingsproses plaasgevind het sodat alle Afrikaanssprekendes - onder andere waarskynlik vanweë politieke redes - gestereotipeer word as outoritêr. 
In die vorming van mites gaan dit, benewens vooroordele en stereotipes, ook om persepsies en om opinies. Nel (1992:8) sê dat persepsies van die ander verwante begrippe onderskei word op grond daarvan dat dit primêr 'n evaluatiewe komponent inhou waar dit, binne 'n bepaalde konteks, gaan om (i) die beoordeling van ánder mense se intensies, (ii) om die versoenbaarheid van diegene wat beoordeel word se waardevoorkeure teenoor dié van die eie persoon en (iii) om die identifiseer van geleenthede en/of bedreigings wat inherent uit die spesifieke omstandighede spruit. Wanneer intuïtiewe klaarheid oor hierdie drietal aspekte ten opsigte van elke saak verkry is, is daar meer duidelikheid oor watter persepsies daar ten opsigte van 'n bepaalde aangeleentheid bestaan.

'n Mening of 'n opinie, daarenteen, word gevorm op grond van die interafhanklike dinamika tussen 'n persoon se (i) oortuigingsraamwerk, (ii) sy waardeoordele, (iii) die gesindhede teenoor en (iv) persepsies van bepaalde sake/aangeleenthede (Nel, 1992:11-13) Volgens Nel (1992:11-13) kan oortuigingsraamwerke gesien word as dié opinies waarvolgens ' $n$ individu homself in sy leefwêreld oriënteer; 'n waardeoordeel as 'n langdurige opinie wat nie geredelik vir ondersoek en wysiging vatbaar is nie; 'n gesindheid as 'n kortstondige opinie wat voortdurend aan ondersoek en wysiging onderwerp word en 'n persepsie as 'n evaluatiewe opinie aan die hand waarvan bepaal word of ' $n$ saak as bedreiging of geleentheid gesien word waarvolgens die posisionering daarteenoor of versoenend of afwysend is. Wanneer persepsies dan, op grond van dié interafhanklike dinamiese prosesse gevorm is, stel dit 'n magtigingstrategie daar waardeur die individu vir homself duidelikheid kry dat 'n spesifieke gedragsrespons op 'n bepaalde aangeleentheid wenslik, geregverdig en moontlik is (Nel, 1992:15). Hierdie proses van regverdiging bring mee dat openbare beelde/images op deurlopende wyse opgeroep, geskep en herskep word. En in die voorstelling van die persepsies en in die voorhou van die binneen buitegroepe speel taalbeelde en metaforiese verwysings ' $n$ kardinale rol.

Toegepas op 'n uitlating soos dié van Boshoff (1994) [weergegee as Aanhaling 1 op p. 128 van hierdie artikel] is dit duidelik dat hy 'n bepaalde opinie het oor Afrikaners se eiewaarde in terme van die Afrikaanse taal en die Afrikaanse gemeenskap. Vanweë die evaluerende aard van dié mening lyk dit of hier van persepsievorming sprake is. Let ter illustrasie op die wyse waarop ánder se intensies gelees word in frase- en woordgebruik soos "Afrikaners het die reg .... ons het die reg ... ons kan aanspraak maak ... wat nie beteken ons kan enigiemand dwing om van ons te hou nie ...". Daarby dui die apologetiese aard van die aanhaling op 'n beoordeling van diegene deur wie die skrywer geantagoniseerd voel se waardevoorkeure, én word dit duidelik dat daar 'n geïmpliseerde onversoenbaarheid daarvan met die skrywer s'n beleef word. Ook is die bedreiginge en geleenthede inherent aan dié waarneming maklik afleibaar: die skrywer sien die stigmatisering van Afrikaners net omdat hulle Afrikaans- 
sprekend is as eksterne bedreiging, terwyl Afrikaanssprekendes se onkritiese gearriveerdheid as interne bedreiging gestel word. Die geleentheid wat die skrywer implisiet deur dié aanhaling stel, is dat Afrikaners op 'n verantwoordbare wyse hul taal en kultuur kan bevorder.

Op grond van dié analise kan die volgende persepsie uit Boshoff (1994) se uitlating afgelei word: hoewel hy krities ingestel is teenoor lede van die binneen die buitegroep, voel hy sterk dat Afrikaners geregtig is op hul eiesoortige kultuurbeoefening, mits hul 'n openheid behou dat ánder mense se aansprake ook geldig is en van hulle s'n sal verskil.

\section{Die simboliese vergestaltings van Afrikaans in oënskou}

Dit behoort op grond van die voorafgaande teoretiese begronding duidelik te wees dat daar 'n sosiopsigologiese dinamika bestaan in die wyse waarop mense met die sake in hul leefwêreld omgaan. Toegepas op die taalpolitieke terrein is dit belangrik om kennis te neem van die spraakgemeenskap se opinie oor taalsake en behoort só 'n kennisname 'n rigtende invloed op optimale taalbeplanning uit te oefen. Kortom, vanuit taalbeplanningshoek is dit belangrik om kennis te neem van die manier waarop spraakgemeenskappe taal en ander simboliese middele inspan om sosiale konstrukte te ver-woord en te be-teken. Die verrekening hiervan behoort tot ' $n$ taalbeplanningsbedeling te kan lei waarin "language planning from below" (Alexander, 1992:143) 'n werklikheid is.

Die doel met dié afdeling is om verkennenderwys te bepaal in watter mate die sosiopsigologie insig bied in die mites wat mettertyd oor Afrikaans ontstaan het en om agter te kom in watter mate die uitmekaarhaal en noukeurige beskouing van sodanige stellings ' $n$ bydrae kan lewer tot die ontmitologisering van Afrikaans. (Hierdie praktiese toepassing van die teoretiese beginsels uit die sosiopsigologie wil nie voorgee om voldoende te wees nie, maar poog om 'n raamwerk daar te stel aan die hand waarvan uitgebreide navorsing oor taalpersepsies gedoen kan word.)

Dit is belangrik om toe te gee dat, wanneer dit gaan om die vasstel van die simboolwaardes van Afrikaans, daar algemeen aanvaar kan word dat Afrikaans nie vir almal dieselfde simboolwaarde het nie: "Vir baie mense was dit die instrument van 'verdeel en heers', vir ander die skerp byl van apartheid, vir baie die juk van onderdrukking" (Du Plessis, 1992c:39). Hierbenewens kan die simboolwaardes van bevryding (uit verskillende politieke oogpunte), hervorming en bemagting waarskynlik ook aan Afrikaans geheg word.

Let ter illustrasie op die volgende aanhalings waarin menings oor die wyse waarop Afrikaans as onderdrukkerstaal manifesteer, uitgespreek word: 
1. Annamart van der Merwe sê in 1992 by die bekendstelling van die Stigting vir Afrikaans (Beeld, 1992-05-19): "Ons moet Afrikaans van hierdie Boereimage bevry."

2. Breyten Breytenbach (Beeld, 1993-11-22) sê blankes aan die Kaap het Afrikaans (wat eers kombuistaal was) gekaap toe hulle besef het dit gee hulle 'n aparte identiteit.

3. Hans du Plessis (Beeld, 1992a-05-08) sê: "Breek af die Afrikaanse taal se eie Berlynse muur! Maak Afrikaans 'n raslose merker van menslike identiteit." Du Plessis sê hy is moeg daarvan om as polities regs gemerk te wees as hy dit net waag om positief teenoor Afrikaans te wees.

4. Breyten Breytenbach (Die Burger, 1998-03-23) sê die heil vir Afrikaans lê nié in laertrek opgesluit nie, maar in vennootskappe met ander tale.

5. Zelda Jongbloed (Beeld, 1992-05-19): "Ek is een van 'n geslag mense wat Afrikaans om politieke redes verwerp het. Baie jare lank het ons mense Afrikaans in terme van uitsluiting en verwerping beleef. Dink maar aan kultuurorganisasies en skole wat nie toeganklik was vir ons mense nie. In reaksie hierop was daar uit my gemeenskap 'n verwerping van Afrikaans en van ons Afrikaansheid. ' $n$ Lang tyd was dit ook politieke strategie. Afrikaans was die simbool van ons onderdrukking, van ons uitsluiting en daarom het daar 'n stigma aan Afrikaans gekleef."

6. Ferdi Greyling (Beeld, 1991-05-28) sê dit is dekades van die NP se apartheidsbeleid wat aan Afrikaans die etiket "taal van die verdrukker" gegee het - die finale vonk in die kruitvat was immers 16 Junie 1976 se opstand. Hy merk ook op dat die wit gemeenskap oortuig is daarvan dat swart bevryding en Afrikaans dinge is wat nie sonder probleme saam kan bestaan nie, hoewel hy toegee "dié siening hou nie meer steek binne die ANC nie".

7. H.J. Schutte verduidelik in 'n brief aan Beeld (1990-08-11) dat baie bruin mense op daardie stadium Afrikaans steeds bly ideologiseer het en as apartheidstaal en witmanstaal bly bestempel het. Daarteenoor: Afrikaans is die taal wat Suid-Afrika wil bevry van verdrukking. Vir baie bruin mense is Afrikaans die taal van bevryding en hervorming."

8. Breyten Breytenbach, André P. Brink, Ampie Coetzee en Frederick van Zyl Slabbert (Die Burger, 1999-03-20) sien hul Afrikaansheid nie as 'n fataliteit of 'n kondisionering nie; dis 'n self-bepalende, ondersoekende, bevraagtekenende, veelkleurige en oop verbasteringsproses wat groei uit baie wortels. 
Om mense se persepsies van Afrikaans vas te stel en te beoordeel, moet die emosionele sentimente soos dit in die taalgebruik na vore kom, afgelei word. Wanneer die voorafgaande aanhalings noukeurig gelees word, word dit duidelik dat algemene populêre waardes en uitsprake oor Afrikaans hiermee uitgedruk word. Hierdie siening weerspieël nie net individuele menings nie, maar gee uiting aan die algemeen aanvaarde mening wat mettertyd ingeburger geraak het, naamlik dat Afrikaans ' $n$ onderdrukkerstaal is. (Dit is insiggewend dat dié mening in hierdie klompie aanhalings almal deur lede van die primêre spraakgemeenskap gehuldig word, én dat algemene afkeer daarvan uitgedruk word.)

Wat in werklikheid volgens Nel (1992:15) gebeur wanneer waarnemers hul menings weergee, is dat sprekers, by wyse van kognitiewe balansaksie, hul éie sentimente teenoor 'n saak (soos dit deur bepaalde beelde/images uitgedruk word) balanseer teenoor ánder mense s'n. Let byvoorbeeld op die reflektering van afkeer deur die voorstelling van negatiewe attribute in die volgende frases wat die band tussen Afrikaans en Afrikanemasionalisme uitdruk: Boere-image, aparte identiteit, Berlynse muur, laertrek. Die gebruik van woorde soos verwerp, verwerping, uitsluiting, stigma, verdrukker in aanhalings 5 en 6 gee 'n aanduiding van die mate waarin Afrikaans met die apartheidsbeleid geassosieer is, terwyl daar ontmitologisering geïmpliseer word deur woorde soos bevry van verdrukking, hervorming in aanhaling 7 en aanhaling 8 se self-bepalende, ondersoekende, bevraagtekenende, veelkleurige, oop verbasteringsproses.

Al dié aanhalings lewer bewys van die sprekers se eie verwysingsraamwerke en die vooroordele wat op grond daarvan gebou is. Hierdie raamwerke tree as't ware op as filters wanneer inkomende inligting verwerk word en lei tot gestereotipeerde beelde waardeur sekere eienskappe bloot aan sake/mense toegeken word op grond van die assosiasie wat dit met 'n ánder saak het.

Op grond van die feit dat Afrikaans met Afrikanernasionalisme geassosieer word, en die sprekers uit aanhalings 1 tot 4 dié band negatief beleef, gee die woordkeuse uitdrukking van hul afkeer van die aparte identiteit wat daarmee geassosieer word. Die evaluatiewe komponent eie aan persepsies spreek onder andere in aanhalings 1 tot 4 daaruit dat waardeoordele uitgespreek word oor die onhoudbaarheid van die band tussen Afrikaans en Afrikanernasionalisme. Dit word op grond van aanhalings 5 en 6 duidelik dat die politieke uitsluiting van bruin mense en die marginalisering wat daarmee saam beleef is, ' $n$ evaluatiewe regverdiging bied vir die negatiewe simboolwaarde van Afrikaans as apartheidsinstrument. Daarenteen sê die evaluatiewe waardeoordeel in aanhaling 7 die teendeel: ten spyte van die feit dat Afrikaans as apartheids- en onderdrukkerstaal bekendstaan, is dit die taal waardeur bevryding bewerkstellig is. Aanhaling 8 gee uitdrukking aan die siening dat die Afrikaanse spraakgemeenskap hul op selfkritiese en inklusiewe wyse moet besighou met sake wat hulle raak. 
Dit word egter pertinent uit dié aanhalings duidelik dat die eie intensies teenoor ander mense s'n afgespeel word, dat bepaalde waardevoorkeure uitgespreek word en dat helderheid verkry word oor die inherente bedreigings of geleenthede ten opsigte van die saak.

\section{Samevatting}

Die doel met hierdie artikel was om vanuit die sosiopsigologie en aanverwante dissiplines ' $n$ teoretiese raamwerk te verskaf vir die analisering van algemene persepsies, veral dan persepsies van taal. Dit is gedoen deurdat bepaal is op watter manier oortuigingsraamwerke, vooroordele en stereotipering betrokke is by persepsievorming. Besondere klem is ook geplaas op die elemente waaruit persepsies bestaan. Die doel hiermee was om 'n analitiese raamwerk op te stel aan die hand waarvan die geykte simboolwaardes (spesifiek dié van Afrikaans as onderdrukkerstaal) ondersoek kon word.

$\mathrm{Na}$ afloop van hierdie voorlopige ondersoek wat grootliks geskoei is op uitlatings oor Afrikaans in die post-apartheidsperiode, is dit moeilik om persepsies klinkklaar gereflekteer te sien in wát gesê word, maar lê die reflektering veral in die mate waartoe afgelei word uit wátter verwysings- en oortuigingsraamwerke menings spruit. Daarby bied bepaalde woordkeuses waardeur sprekers én luisteraars se kognitiewe kategoriseringsprosesse duidelik word, besondere insig in die wyse waarop die omgewing waargeneem word.

Met betrekking tot persepsies oor Afrikaans is dit interessant dat geykte simboliese vergestaltings, mense se eie waardestelsels, hul eie vooroordele en posisionering teenoor dit wat met die taal saamhang, weerspieël word in die wyse waarop hulle die taal beskou.

Oor die sin van 'n wetenskaplike analise van die mites van Afrikaans kan gesê word dat dit in die besonder lê in die bydrae wat dit behoort te lewer tot die ontmaskering van beelde wat mettertyd op onkritiese wyse met Afrikaans geassosieer geraak het. Eers wanneer die aftakeling van die mites oor Afrikaans volledig plaasgevind het, kan, in die woorde van die aanhaling wat as proloog tot die artikel gevoeg is, gewerk word aan die vervulling van Afrikaans se volle funksiepotensiaal in meertalige verband.

\section{Bibliografie}

Alexander, N 1992. Language planning from below. In: Herbert, Robert K (ed.) Language and society in Africa: The theory and practice of Sociolinguistics. Johannesburg : Witwatersrand University Press. p. 143-149.

Alexander, N. 1997. Probleme verwag in pogings om 'universele kultuur' in Suid-Afrika te skep. Die Burger. 19, Mei 29.

Baron, R A \& Byrne, D (eds.) 1991. Social Psychology. Understanding human interaction Boston : Allyn \& Bacon. 
Boshoff, C. 1994. Toekoms is veeltalig Lot van Afrikaans, ander Afrikatale 'verknoop' Beeld 8, Mei 11.

Breytenbach, B. 1993. "Daai taal!" skud sy negatiewe beeld af Maar Breyten wil steeds monument opblaas. Beeld. 3, Nov. 22.

Breytenbach, B. 1998. "Leef andersheid uit op taalvlak, vra Breyten". Die Burger. 2, Maart 23.

Breytenbach, B., Brink, A., Coetzee, A \& Slabbert, F. Van Zyl 1990. "Watse wiese Afrikaners?" Die Burger: 8, Maart 20.

Brown, R 1995. Prejudice: Its social psychology. Oxford : Blackwell.

Du Plessis, Hans. 1992a. "Breek af die Afrikaanse se eie Berlynse muur!" Maak Afrikaans 'n raslose merker van menslike identiteit. Beeld: 9, Mei 8.

Du Plessis, Hans 1992b. Die konsolidasie van die Afrikaanse taalgemeenskap. Literator, 13(2):69-75.

Du Plessis, Hans 1992c. En nou Afrikaans? Pretoria : Van Schaik.

Du Toit, Dirk C. 1998. Vervorm taal en Afrikanerskap. Die Burger. 10, Mei 8.

Du Toit. K. 1998. Vars bries oor taal in ANC? Die Burger. 3, April 23.

Edwards, J. 1994. Multilingualism. London : Routledge.

Fourie, P.J. 1991 Media, mites, metafore en die kommunikasie van apartheid Communicatio, $17(1): 2-6$.

Greyling, F. 1991. Die ANC en Afrikaans. Baie positiewe geluide kom uit swart politieke kraal. Beeld: 15, Mei 28.

HAT kyk Odendal

Jongbloed, Z. 1992. Mening opgeneem in artikel: Afrikaans is 'n huis vir ons. Beeld 11, Mei 19.

Nel, P. 1992. Perceptions, images and stereotypes in Soviet-South African relations - a cognitive-interpretative perspective. Stellenbosch : Universiteit van Stellenbosch. (Annale).

Oakes, P.J., Haslam, S.A \& Tumer, J.C. 1994. Stereotyping and social reality. Oxford : Blackwell.

Odendal, F.F. (red.) 1994. HAT. Verklarende handwoordeboek van die Afrikaanse taal. Johannesburg : Perskor.

Pokpas, L. \& Van Gensen, A. 1992. Die simboliese betekenis van Afrikaans In: Webb, V N. (red.) Afrikaans na apartheid Pretoria : Van Schaik p. 165-178.

Schutte, H.J 1990. Die taal van hervorming Beeld: 9, Aug. 11.

Steenberg, DH. 1992. Mite In. Cloete, T.T. (red.) Literêre terme en teorieë. Pretoria : HAUM-Literêr.

Swanepoel, P. 1992. Taal, emosies en die toekoms van Afrikaans. In: Webb, V.N (red) Afrikaans na apartheid Pretoria : Van Schaik. p. 121-163.

Van den Heever, R \& Verwoerd, M. 1998 Grondwet beskerm Afrikanerkultuur. Die Burger: 10, April 20.

Van der Merwe, A 1992. Mening opgeneem in artikel: Afrikaans is ' $n$ huis vir ons. Beeld: 11, Mei 19.

Webb, V., Dirven, R. \& Kock, E. 1992. Afrikaans: feite en interpretasies. In: Webb, V.N. (red.) Afrikaans na apartheid Pretoria : Van Schaik. p. 25-67. 
